\title{
Title: STABILITY OF NUCLEAR FORCES VERSUS WEAPONS OF MASS \\ DESTRUCTION
}

Author(s):

Gregory H. Canavan, P-DO

\author{
RFCEIVED \\ APR 061998 \\ OSTI
}

\section{Submitted to:}

For discussions outside the Laboratory

Date: December 1997
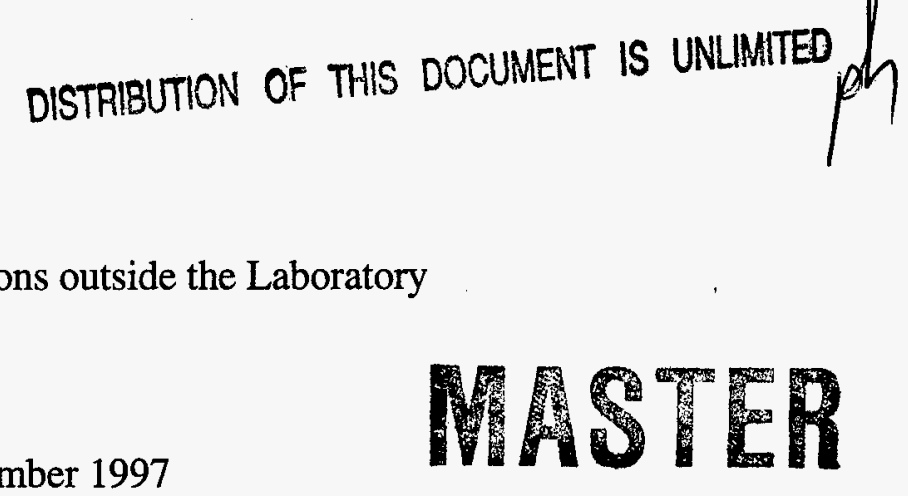

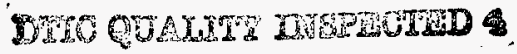

\section{3}

Los Alamos

NATIONAL LABORATORY

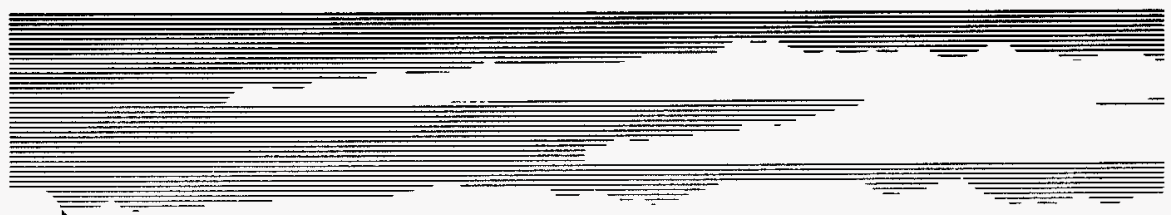

Los Alamos National Laboratory, an affirmative action/equal opportunity employer, is operated by the University of California for the U.S. Department of Energy under contract W-7405-ENG-36. By acceptance of this article, the publisher recognizes that the U.S. Government retains a nonexclusive, royalty-free license to publish or reproduce the published form of this contribution, or to allow others to do so, for U.S. Government purposes. The Los Alamos National Laboratory requests that the publisher identify this article as work performed under the auspices of the U.S. Department of Energy. 


\section{DISCLAIMER}

This report was prepared as an account of work sponsored by an agency of the United States Government. Neither the United States Government nor any agency thereof, nor any of their employees, makes any warranty, express or implied, or assumes any legal liability or responsibility for the accuracy, completeness, or usefulness of any information, apparatus, product, or process disclosed, or represents that its use would not infringe privately owned rights. Reference herein to any specific commercial product, process, or service by trade name, trademark, manufacturer, or otherwise does not necessarily constitute or imply its endorsement, recommendation, or favoring by the United States Government or any agency thereof. The views and opinions of authors expressed herein do not necessarily state or reflect those of the United States Government or any agency thereof. 


\title{
STABILITY OF NUCLEAR FORCES VERSUS WEAPONS OF MASS DESTRUCTION
}

\author{
Gregory H. Canavan
}

Crisis stability analysis is extended to weapons of mass destruction (WMD). Nuclear and WMD can be balanced against one another for undispersed WMD forces, but dispersal degrades stability. Irrational or aggressive behavior further degrades stability, particularly at the low dispersals thought to be stable.

The model derived for nuclear missile exchanges is used to describe the interaction between two forces, of which one has a nuclear weapons and the other has weapons of mass destruction (WMD). The model equations are solved analytically for exchanges, costs, and stability indices by analytically minimizing the cost of first strikes. The analysis is restricted to theater operations, as WMD are inferior to nuclear weapons in strategic counter force operations, but quite adequate for theater operations against exposed forces. The analysis treats only intheater forces as companion papers show that ex-theater forces, which enter as survivable forces, cancel out of the theater balances treated here.

Optimal nuclear weapon and WMD allocations are proportional to the opponent's carriers and inversely proportional to one's own weapons. Thus, as WMD increase, WMD allocations to nuclear forces fall, reflecting a shift from damage limiting to inflicting damage with surviving forces. Nuclear weapon kill probabilities degrade rapidly against dispersed forces. As they fall, their allocation to WMD falls sharply as they become ineffective and are reallocated to value. Thus, damage limiting is primarily effective for undispersed forces, which produces an incentive for the nuclear side to use his weapons while they are still effective.

First strikes are complementary to these allocations, so as kill probabilities decrease, the nuclear side's first strikes increase and the WMD side's survivability and second strike increases. Thus, the difference between the nuclear side's second and first strikes decrease due to the increase in his first strike, and the difference between the WMD side's second and first strikes increase due to the increase in his second strikes.

The stability of singlet WMD forces is negative for the small probabilities corresponding to the expected full dispersal, where it is dominated by the WMD. For triplet WMD carriers, stability is determined equally by nuclear and WMD at large kill probabilities; by WMD at small kill probabilities, where they again become quite negative.

The possibility that an opponent might use a different stability calculus and arrive at a different assessment can be modeled through the model parameters that represent relative damage preference. A WMD opponent with a strong preference for damage would shift his allocation from missiles to value to increase his first strikes on value by a like amount, which 
would strongly decreases stability at large kill probabilities. Thus, irrational evaluation could decrease stability in the region where it is generally thought deterrence should be effective.

Overall, the extension of the nuclear crisis stability formalism to forces with WMD is natural and fruitful. It is straightforward to relate WMD to missile numbers and weapons. That makes it possible to treat the reduced effectiveness of nuclear weapons against dispersed forces, i.e., the effectiveness of dispersal in increasing the survivability for WMD, which significantly reduces overall stability.

Exchange Model is an aggregated, probabilistic exchange between the two forces, which treats the WMD forces in terms of nuclear force equivalents. The two sides are labeled by the "unprime" and "prime" as nationality-neutral labels are appropriate in discussing strikes of sizes that could be executed by any of a half dozen countries. The unprime forces are treated as being composed of $\mathrm{M}$ missiles with $\mathrm{m}$ weapons each, although the weapons might actually be mounted on aircraft, have different numbers of weapons per carrier, etc. $M$ can represent either the number of missiles, missile sites, or the number of bases on which the missiles or aircraft are based, as WMD could destroy or incapacitate the weapons located on any. The total number of nuclear weapons is $\mathrm{mM}$. Survivability of in-theater missiles and aircraft is an important feature, which is studied by varying the kill probability of opposing forces in a companion paper on the stability of conventional forces.

The opposing side, denoted by "prime," in accord with the symbols used for its forces, is taken to have chemical, biological, or other WMD of $\mathrm{m}$ ' weapons on each of M' carriers for a total of m'M' nuclear weapon equivalents. $\mathrm{M}^{\prime}$ is the number of launchers or transporters; it also represents the number of points that would have to be targeted to destroy one of these units. Each WMD has a value killing potential of $m$ ' targets. The lethality of biological weapons approaches that of nuclear weapons, $\mathrm{m}^{\prime} \sim 1$ air base or city per weapon, so nuclear and WMD are roughly commensurate. WMD forces seek to achieve survivability through dispersal, which is studied below by degrading the nuclear force's kill probability to model varying levels of dispersal.

The intent here is not to develop a detailed model of WMD war, but to evaluate the extent to which the models developed earlier for nuclear war can be applied in a logical fashion to treat the stability of engagements involving forces that have both nuclear weapons and WMD. Thus, the analysis below maintains the symbols used in the earlier analyses in order to simplify analogies between the nuclear and mixed forces. Thus, exchanges between forces are modeled in terms of the first, F, and second, S, strikes unprime could deliver to prime and the first, F', and second, S', strikes prime could deliver to unprime, as derived in the Appendix. ${ }^{1}$ The discussion below identifies the nuclear power as unprime and the WMD power as unprime, although the results can easily be interchanged to view stability from the opposite perspectives. 
Optimum allocation of weapons results in the allocation of a fraction $f_{o}$ of unprime's first strike mM to the M' known prime WMD sites, where from the Appendix

$$
f_{0}=\left(M^{\prime} / m M l n q\right) \ln \left(-L^{\prime} / k^{\prime} \operatorname{lnq}\right) \text {, }
$$

where $p=1-q$ is his kill probability $L$ his relative preference for inflicting damage to prime and preventing damage to self, and other parameters are defined in the Appendix. The equation for prime's first strike allocation is the conjugate of Eq. (1)

$$
f_{0}{ }^{\prime}=\left(M / m^{\prime} M^{\prime} \operatorname{lnq}\right) \ln \left(-L^{\prime} k / k^{\prime} m l n q^{\prime}\right) \text {. }
$$

Figure 1 shows $f_{o}$ and $f_{o}$ ' for $m^{\prime}=1$ and 3 (single and triple WMD warhead missiles) as functions of unprime's kill probability $p$. In the calculations below, the nuclear forces are maintained at $\mathrm{mM}=12 \times 5=60$ weapons, against which prime weapons have kill probability p' $=0.6$. The variation of $\mathrm{p}$ models the effect of dispersal of the WMD. They should be fairly easy to kill when undispersed, i.e., $\mathrm{p} \sim$ unity; but hard to find or kill when dispersed, $\mathrm{p}$ low.

The curve for singlet warheads (" $f$ single") shows that for $p \sim 1, f_{o}$ increases slightly as $p$ falls, reaching a maximum $\sim 0.7$ at $\mathrm{p} \sim 0.7$ for these parameters. For smaller values of $\mathrm{p}, \mathrm{f}_{\mathrm{o}}$ falls rapidly to zero. The curve for triplet warheads ("f triple") shows that $f_{0}$ again increases as $p$ falls, reaching a maximum $\sim 0.7$ at $p \sim 0.3$ before falling to zero for small $p$. For $p$ large, unprime's optimal allocation $f_{o}$ is largely to prime missiles, to minimize damage to self. However, for $p$ small, the effectiveness of damage limiting falls rapidly, and $f_{o}$ with it. This fall in effectiveness produces an incentive for the nuclear side to use his weapons while they are still effective, which increases the probability of a premature response in a crisis

The two curves for $f_{o}$ ' are constant because they depend on $p$ ', not $p$. The curve for triplet WMD is lower than that for singlets by a factor $~ 3$ by Eq. (2). The sensitivity to p' is studied in the companion paper on conventional force stability.

First strikes shown in Fig. 2 are complementary to the allocations of Fig. 1. For singlets, for $\mathrm{p}>0.6$ unprime allocates $\sim 70 \%$ of his weapons to WMD so he has a first strike of only $\sim 0.3$ $x 60 \sim 20$ weapons on value. For smaller $p, f_{0} \sim 0$, and $F$ increases to $\sim 60$. For triplets, unprime has a minimum at $\mathrm{p} \sim 0.4$, although the first strikes are larger for both larger and smaller $\mathrm{p}$.

$f_{o}$ ' is independent of $p$, so it is constant. It scales as $\mathbf{M} / \mathbf{m}^{\prime} \mathbf{M}^{\prime}$, which is held constant as $\mathrm{m}$ ' is changed, so prime's allocation and first strikes are constant and the same for both $\mathrm{m}$ '.

Survival probability depends on the average number of weapons delivered on each known target, which optimizes at

$$
\mathrm{r}=\mathrm{fmM} / \mathrm{M}^{\prime}=\ln \left(-\mathrm{Lk}^{\prime} / \mathrm{km} \text { 'lnq }\right) / \mathrm{lnq},
$$

The resulting survival probability for a prime weapon is

$$
\mathrm{Q}^{\prime} \approx \mathrm{q}^{\mathrm{r}}=-\mathrm{Lk}^{\prime} / \mathrm{km} \text { 'lnq, }
$$


which is largely determined by $\mathrm{L} / \mathrm{m}^{\prime}$ and $\mathrm{p}$. Figure 3 shows $\mathrm{Q}$ and $\mathrm{Q}$ ' as functions of $\mathrm{p}$. For singlet weapons ( $\left.Q s^{\prime}\right), Q$ ' increases rapidly as $p$ falls, reaching unity at $p \sim 0.5$ where nuclear strikes become ineffective. For triplets, $Q$ ' increases less rapidly for $p$ large, but continues to rise after $\mathrm{p} \sim 0.5$, reaching unity by $\mathrm{p} \sim 0.1$. Because

$$
\mathrm{Q} \approx-\mathrm{L}^{\prime} \mathrm{k} / \mathrm{k}^{\prime} \mathrm{mln} \mathrm{q}^{\prime}
$$

is independent of $\mathrm{p}$ and $\mathrm{L} / \mathrm{m}$ does not change in this calculation, $\mathrm{Q}$ is constant $\sim 0.5 / 10 \mathrm{x} \ln 0.4$.. $\sim 0.05$ for both $\mathrm{m}^{\prime}=1$ and 3 . In the absence of survivable forces, $\mathrm{S}=\mathrm{QmM}$, so second strikes are just a relabeling of the values of $Q$ in Fig. 3 by a factor of $m M=60$, as shown at the right.

Stability indices are defined and derived in the Appendix. The index for unprime is

$$
\mathrm{J} \approx \mathrm{k}\left(\mathrm{S}^{\prime}-\mathrm{F}^{\prime}\right)+\mathrm{Lk}(\mathrm{S}-\mathrm{F})
$$

by conjugation, that for prime is

$$
J^{\prime} \approx k^{\prime}(S-F)+L^{\prime} k\left(S^{\prime}-F^{\prime}\right) \text {. }
$$

The common factors $S^{\prime}-F^{\prime}$ and $S-F$ are shown in Fig. 4. From Fig. 3, $S \approx 0$, so $S-F$ are $\approx-F$ for both singlets and triplets Thus, $\mathrm{S}-\mathrm{F}$ is largely determined by first strike allocations. The curves for S' - F' track S' of Fig. 3, because those for F' in Fig. 2 are constant.

Figure 5 shows $\mathrm{J}, \mathrm{J}$ ', and the overall stability index $\mathrm{J}+\mathrm{J}$ ' for singlets. The top curve is $\mathrm{J}$. For large $p$ it results from the addition of $S-F$ and $S^{\prime}-F^{\prime} \sim-F+\left(S^{\prime}-F^{\prime}\right)$, each of which is negative. For $\mathrm{p}<0.5 \mathrm{~S}^{\prime}$ - $\mathrm{F}^{\prime}$ increases and $\mathrm{S}$ - $\mathrm{F}$ decreases sharply and then saturates, so that $\mathrm{J}$ results from the cancellation between large positive and negative quantities. The middle curve is for $J^{\prime}$, which for $p>0.3$ results from the addition of two negative numbers. that decrease in magnitude as $\mathrm{p}$ decreases. For $\mathrm{p}<0.3, \mathrm{~S}^{\prime}-\mathrm{F}^{\prime}$ increases sharply and $\mathrm{S}-\mathrm{F}$ decreases sharply, so that $J^{\prime}$ becomes the cancellation between two large numbers of opposite sign.

The middle curve for $\mathrm{J}+\mathrm{J}$ ' represents their sum. For $\mathrm{p}$ large, it is the sum of large, negative $\mathrm{J}$ and $\mathrm{J}^{\prime}$. For $\mathrm{p}<0.5$ it is dominated by, and approximately equal to, $\mathrm{J}^{\prime}$. Thus, for singlets, the WMD side dominates the overall stability index at small $\mathrm{p}$, the likely dispersed condition, where the overall index is quite negative.

Figure 6 shows the stability indices for triplets, in which the peaks seen in the singlet indices are pushed to smaller $p$. The top curve is $J$, which for $p>0.3$ is very close to $J$ ', so the combined index is $\sim 2 \mathrm{~J}$. For $\mathrm{p}<0.3$ the singlet curve rises towards zero and the triplet curve falls, so the combined index is $\sim \mathrm{J}$ '. Thus, for large $\mathrm{p}$, stability is determined about equally between the nuclear and WMD forces, and for small p, the WMD side determines the stability index, which becomes negative for the small $\mathrm{p}$, dispersed condition.

Damage preference. A concern in addressing an opponent with WMD is the possibility that he might use a different calculus than the rational process above to arrive at a different assessment of the stability of a given configuration. That possibility can be modeled using the 
above model because it contains parameters, $\mathrm{L}$ and $\mathrm{L}$ ' that explicitly represent the relative preference of each side for inflicting damage on the other and preventing damage to self. To the extent that preferring inflicting damage on the other to preventing damage to self can be viewed as self-destructive or irrational, large values of L' can be used to model such behavior.

Below, $L$ is held at a nominal value $L=0.5$ as a baseline, and $L^{\prime}$ is varied upward. $L^{\prime}=2$ represents a WMD opponent who is twice as interested in inflicting as preventing damage or 4 times as interested as his rational opponent. This $L$ ' reduces prime's optimal allocation to missiles by about a factor of $2(\sim \ln 4)$ and increases his first strikes slightly, which increases unprime's survival probability a factor of $\sim 4$. The consequence can be seen by contrasting the indices of Fig. 5 for rational opponents with $L^{\prime}=L^{\prime}=0.5$ to Fig. 7 for $L=0.5$ and $L^{\prime}=2$. The former has structure below $p=0.5$; the latter has none. The values at small $p$ become slightly less negative, but the values for large $p$ become much more negative, and the stabilizing bumps at $p$ 0.5 are eliminated, so the decrease in stability with $\mathrm{p}$ becomes monotonic and strong. $\mathrm{By} \mathrm{p}=1$, the combined index reaches a value twice as negative as for rational opponents.

Larger L' produces greater stability losses, but the main point is the qualitative observation that irrational behavior, i.e., increasing the WMD opponent's damage preference L' strongly decreases stability in the $p>0.5$ region where deterrence is thought to be effective.

Summary and conclusions. The model derived for nuclear missile exchanges is used to describe the interaction between two forces, of which one has a nuclear weapons and the other has WMD. The model equations are solved analytically for exchanges, costs, and stability indices by analytically minimizing the cost of first strikes.

Optimal nuclear weapon and WMD allocations are proportional to their number of opponent carriers and inversely proportional to one's own weapons. Thus, WMD allocations to nuclear forces fall as WMD increase, reflecting a shift from damage limiting to inflicting damage with forces that survive nuclear attack. Nuclear weapons' kill probability degrades rapidly against dispersed forces. As their kill probability falls, their allocation to WMD falls sharply as weapons become ineffective against dispersed forces and are reallocated to value. Thus, damage limiting is primarily effective for undispersed forces, which produces an incentive for the nuclear side to use his weapons while they are still effective.

Each sides' first strikes are complementary to these allocations, so the nuclear side's first strikes drop at intermediate kill probabilities and increase for large values. As kill probability decreases, the WMD side's survivability and second strike increases. Thus, the nuclear side's second minus first strikes decrease due to the increase in his first strike at low kill probability, and the WMD side's second minus first strikes increase due to the increase in his second strikes.

The stability of the equal forces with singlet WMD is negative for most values of nuclear kill probabilities—and quite negative for the small probabilities corresponding to the expected 
full dispersal, where stability is dominated by the WMD side. For triplets, stability is determined about equally by nuclear and WMD at large kill probabilities. At small kill probabilities, the side with WMD determines the stability index, which becomes quite negative for small $\mathrm{p}$

The possibility that an opponent might use a different calculus and arrive at a different assessment of stability can be modeled through the model parameters introduced to represent relative damage preference. A WMD opponent with a damage preference four time's his opponents shifts his allocation from missiles to value by a factor of 2 to increase his first strikes on value by a like amount, which monotonically and strongly decreases stability at large kill probabilities. Thus, irrational evaluation could decrease stability in the region where it is generally thought deterrence should be effective.

Overall, the extension of the nuclear crisis stability formalism to forces with WMD is natural and fruitful. It is straightforward to relate WMD to missile numbers and weapons. The major new element is the reduced effectiveness of nuclear weapons against dispersed forces, i.e., the effectiveness of dispersal as a means of gaining survivability for WMD, which significantly reduces the stability of configurations with dispersed WMD. For the equal-capability forces treated here, high nuclear kill probabilities can be used to offset WMD, but they do so only as long as the WMD are undispersed. 


\section{Appendix: Exchange Model}

If unprime strikes first and a fraction $f$ of his weapons is directed at prime's vulnerable missiles, his first strike on prime's value targets is

$$
\mathrm{F}=(1-\mathrm{f}) \mathrm{mM} \text {. }
$$

The average number of weapons on each prime vulnerable units is

$$
\mathrm{r}=\mathrm{fmM} / \mathrm{M}^{\prime} \text {. }
$$

For $r$ large, the average probability of survival of a prime target is ${ }^{2}$

$$
\mathrm{Q}^{\prime} \approx \mathrm{q}^{\mathrm{r}} \approx \mathrm{e}^{\mathrm{fW}} \mathrm{lnq} / \mathrm{M}^{\prime},
$$

where $\mathrm{p}=1-\mathrm{q}$, is the attacking missile's single shot probability of kill. Prime's second strike is

$$
S^{\prime}=m^{\prime} M^{\prime} Q^{\prime} \approx m^{\prime} M^{\prime} q^{r} \text {, }
$$

which is used to strike or seize value, as forces remaining at the end of the exchange are taken to have no value. The corresponding equations for prime's first strike can be derived either by repeating the logic from his perspective or simply by conjugating the equations above, i.e., interchanging primed and unprime symbols in Eq. (1)

$$
F^{\prime}=\left(1-f^{\prime}\right) m^{\prime} M^{\prime} \text {. }
$$

Similarly, unprime's second strike is given by conjugation as

$$
\mathrm{S}=\mathrm{mMQ} \approx \mathrm{mMq}^{\prime} \mathrm{r} \text {, }
$$

Costs. First and second strikes are converted into first and second strike costs through exponential approximations to the fractions of military value targets destroyed. The cost to unprime for striking first is approximated by

$$
\mathrm{C}_{1}=\left(1-\mathrm{e}^{-\mathrm{k} \mathrm{S}^{\prime}}+\mathrm{Le} \mathrm{e}^{-\mathrm{k}^{\prime} \mathrm{F}}\right) /(1+\mathrm{L})
$$

where $1 / \mathrm{k}^{\prime} \approx 100$ is the number of prime military value targets unprime holds at risk, $1 / \mathrm{k}^{\prime} \approx 100$ is the number of unprime military value targets prime holds at risk, ${ }^{3}$ and $\mathrm{L}$ is a parameter that characterizes unprime's relative preference for damage to prime and preventing damage to self. ${ }^{4}$ While these two costs are formally incommensurate, as they represent damage to different sides, it is conventional to approximate a total cost by taking their sum as a weighted sum with a parameter $\mathrm{L}$, which is plausible but not unique. ${ }^{5}$ For relatively small strikes,

$$
(1+\mathrm{L}) \mathrm{C}_{1} \approx \mathrm{k} S^{\prime}+\mathrm{L}\left(1-\mathrm{k}^{\prime} \mathrm{F}\right),
$$

which is small. The cost to unprime for striking second is

$$
(1+\mathrm{L}) \mathrm{C}_{2}=1-\mathrm{Le}^{-\mathrm{kF}^{\prime}}+\mathrm{Le} \mathrm{e}^{\prime} \mathrm{S} \sim \mathrm{kF} \mathrm{F}^{\prime}+\mathrm{L}\left(1-\mathrm{k}^{\prime} \mathrm{S}\right) \text {. }
$$

First and second strike costs for prime can be obtained either by re-deriving these results from prime's viewpoint or by conjugating Eqs. (7) and (9), which introduces a second constant L', reflecting prime's relative attack preference ${ }^{6}$ 
Indices. While there is some arbitrariness in converting $\mathrm{C}_{1}$ and $\mathrm{C}_{2}$ into stability indices, it is conventional to use the ratio of first and second strike costs, $I=C_{1} / C_{2}$, as a stability index for unprime, and $\mathrm{I}^{\prime}=\mathrm{C}_{1}{ }^{\prime} / \mathrm{C}_{2}$, as a stability index for prime. When they are large, there is no advantage to striking first. When they are small, there is an apparent advantage, which may be perceived as an incentive to attack first in a crisis. For unequal forces, the product of the stability indices of the two sides is used as a compound index

$$
\text { Index }=\mathrm{I} \times \mathrm{I}^{\prime}=\left(\mathrm{C}_{1} / \mathrm{C}_{2}\right)\left(\mathrm{C}_{1}{ }^{\prime} / \mathrm{C}_{2}{ }^{\circ}\right) \text {. }
$$

For small $\mathrm{F}$ and $\mathrm{S}$, the stability index is approximately ${ }^{8}$

$$
\mathrm{I}=\mathrm{C}_{1} / \mathrm{C}_{2} \approx 1+\left(\mathrm{C}_{1}-\mathrm{C}_{2}\right)(1+\mathrm{L}) / \mathrm{L},
$$

so an appropriate stability index for unprime for small forces is

$$
\mathrm{J}=(\mathrm{I}-1) \mathrm{L}=(1+\mathrm{L})\left(\mathrm{C}_{1}-\mathrm{C}_{2}\right) \approx \mathrm{k}\left(\mathrm{S}^{\prime}-\mathrm{kF} \mathrm{F}^{\prime}\right)+\mathrm{Lk}^{\prime}(\mathrm{S}-\mathrm{F}),
$$

for which $J \approx 0$ represents neutral stability. It is clear from the appearance of $S^{\prime}$ and $F$ ' in this equation that the stability as seen by unprime depends on factors that will influence prime's perception of stability as well. By conjugation,

$$
J^{\prime} \approx k^{\prime}(S-F)+L^{\prime} k\left(S^{\prime}-F^{\prime}\right) \text {. }
$$

Their joint difference stability index is

$$
\begin{aligned}
\mathrm{J}+\mathrm{J}^{\prime}= & \approx \mathrm{k}\left(\mathrm{S}^{\prime}-\mathrm{F}^{\prime}\right)+\mathrm{Lk}^{\prime}(\mathrm{S}-\mathrm{F})+\mathrm{k}^{\prime}(\mathrm{S}-\mathrm{F})+\mathrm{L}^{\prime} \mathrm{k}\left(\mathrm{S}^{\prime}-\mathrm{F}^{\prime}\right) \\
& =\mathrm{k}^{\prime}(1+\mathrm{L})(\mathrm{S}-\mathrm{F})+\mathrm{k}\left(1+\mathrm{L}^{\prime}\right)\left(\mathrm{S}^{\prime}-\mathrm{F}^{\prime}\right) .
\end{aligned}
$$

For the $\mathrm{k}^{\prime}=\mathrm{k}^{\prime}=1 / 100$ and $\mathrm{L}=\mathrm{L}^{\prime}=0.5$ example treated here, this reduces to

$$
\mathrm{J}+\mathrm{J}^{\prime}=2 \mathrm{k}(1+\mathrm{L})\left[(\mathrm{S}-\mathrm{F})+\left(\mathrm{S}^{\prime}-\mathrm{F}^{\prime}\right)\right]
$$

although even for $k=k^{\prime}$ and $L=L^{\prime}$, it $S-F \neq S^{\prime}-F^{\prime}$ unless the forces are equal, which is not the case of interest here.

Optimal attack allocation for unprime amounts to choosing $\mathrm{f}$ that minimizes his first strike cost $\mathrm{C}_{1},{ }^{9}$ which can be accomplished in one of two ways. The first is by solving Eq. (7) for the value of $f$ that minimizes $C_{1}$. While for large forces the equation is transcendental, it can be solved simply by iteration. The second was is by differentiating Eq. (7) with respect to f, setting the result to zero, and solving for $\mathrm{f}$. For small forces $(F, S<1 / \mathrm{k})$ for which Eq. (7) reduces to Eq. (8), and it to

$$
(1+\mathrm{L}) \mathrm{C}_{1} \approx \mathrm{km} \mathrm{M}^{\prime} \mathrm{M}^{\prime} \mathrm{fmMlnq}^{\mathrm{m}} \mathrm{M}^{\prime}+\mathrm{L}\left[1-\mathrm{k}^{\prime}(1-\mathrm{f}) \mathrm{mM}\right],
$$

which is sufficiently accurate for moderate forces. ${ }^{10}$ Its derivative with respect to $\mathrm{f}$ has a minimum at

$$
f_{O}=\left(M^{\prime} / m M l n q\right) \ln \left(-L k^{\prime} / k^{\prime} \operatorname{lnq}\right) \text {. }
$$

The equation for prime's first strike allocation $\mathrm{f}_{\mathrm{O}}{ }^{\prime}$ is the conjugate of Eq. (14) 


\section{References}

1. G. Canavan, "Stability of Unsymmetric Forces," Los Alamos report LA-UR-97-1133, March 1977.

${ }^{2}$. G. Canavan, "Probability of Sur ival from Multiple Weapon Attacks," Los Alamos report LA- . UR-97-664, February 1997.

3 . G. Canavan, "Costs of Strikes Between Vulnerable Missile Forces," Los Alamos report LAUR-97-663, February 1997.

${ }^{4}$. G. Kent and R. DeValk, "Strategic Defenses and the Transition to Assured Survival," RAND Report R-3369-AF, October 1986.

5. G. Canavan, "Stability at Symmetric Low Force Levels," Los Alamos report LA-UR-96-1631, May 1996.

6. G. Canavan, "Destabilizing Effects of Perceptions," Los Alamos LA-UR-96-1742, May 1996

7. G. Canavan, "Impact of Differing Metrics on Crisis Stability Analyses," A. Zichichi ed., International Seminar on Nuclear War and Planetary Emergencies, 18th Session: Global Stability Through Disarmament (London, World Scientific, 1993).

8. G. Canavan, "Stability Issues in Reconstitution by Weapon Addition," Los Alamos LA-UR97-3114, August 1997, Eqns. (25)-(27).

9. A. Piontkovsky, "New Paradigm of Strategic Stability," A. Zichichi ed, International Seminar on Nuclear War and Planetary Emergencies (London, World Scientific, 1993)

${ }^{10}$. G. Canavan, "Linearity of Missile Allocation Optimization," Los Alamos report LA-UR-973569, August 1997. 



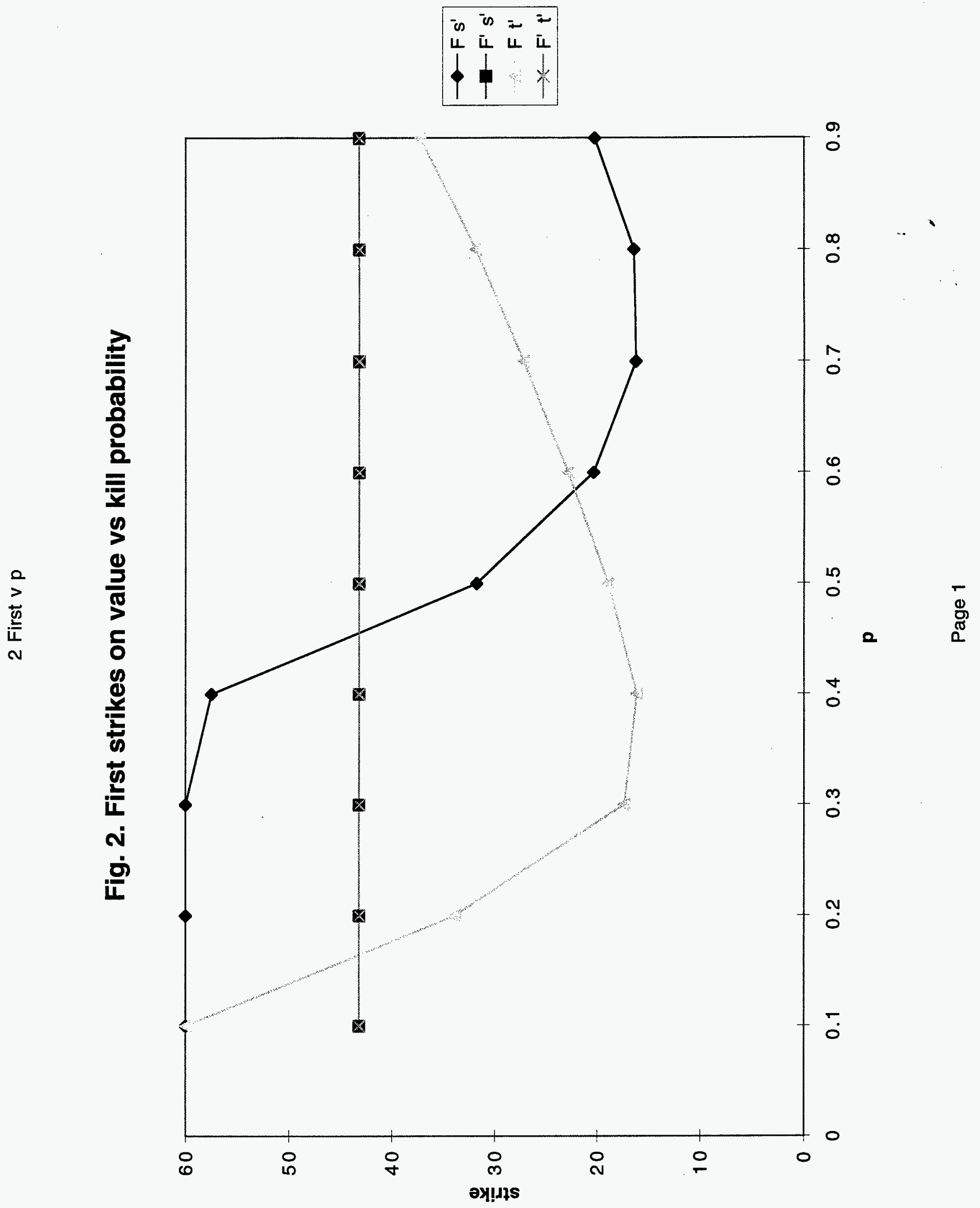




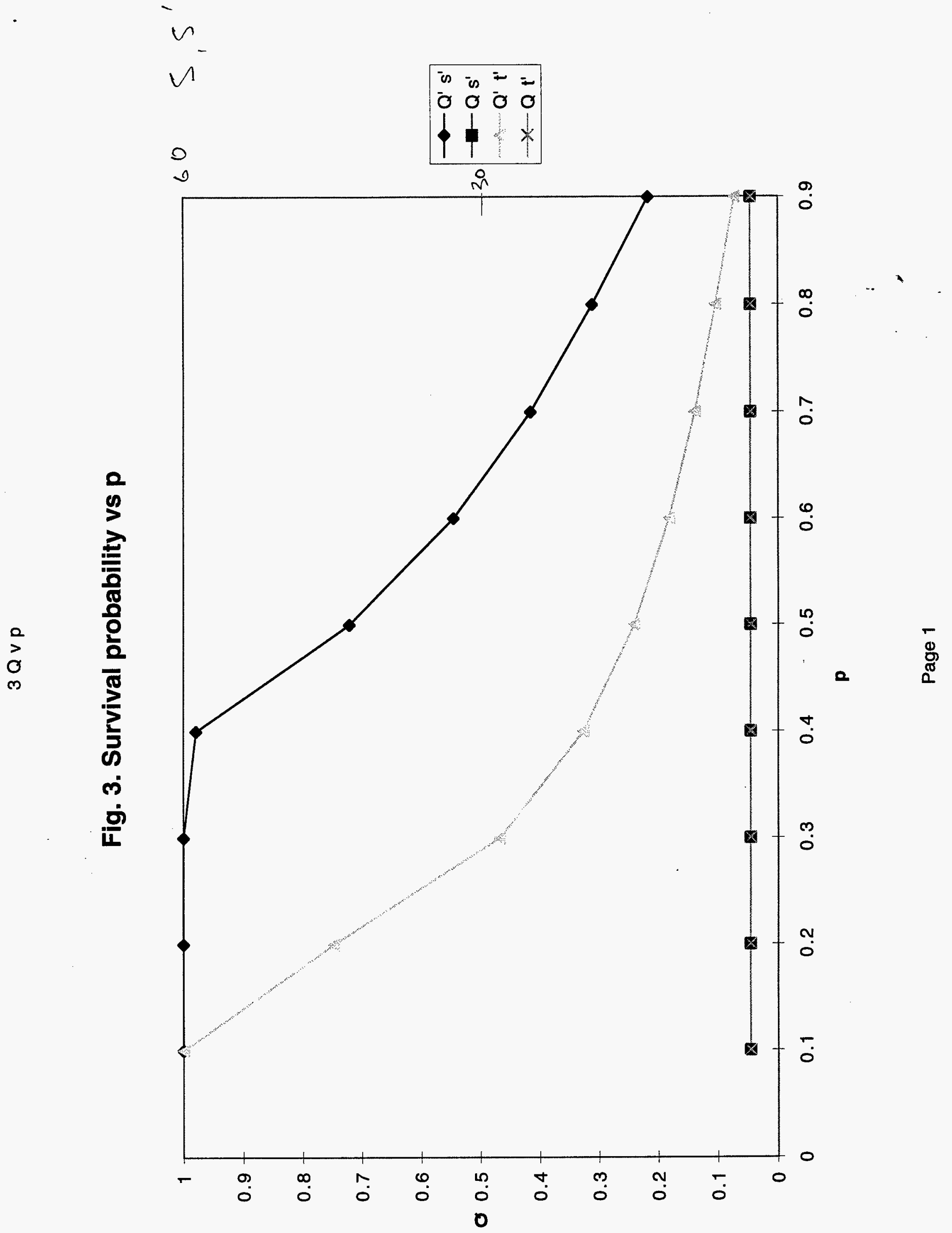


Fig. 4. Strike differences vs $p$

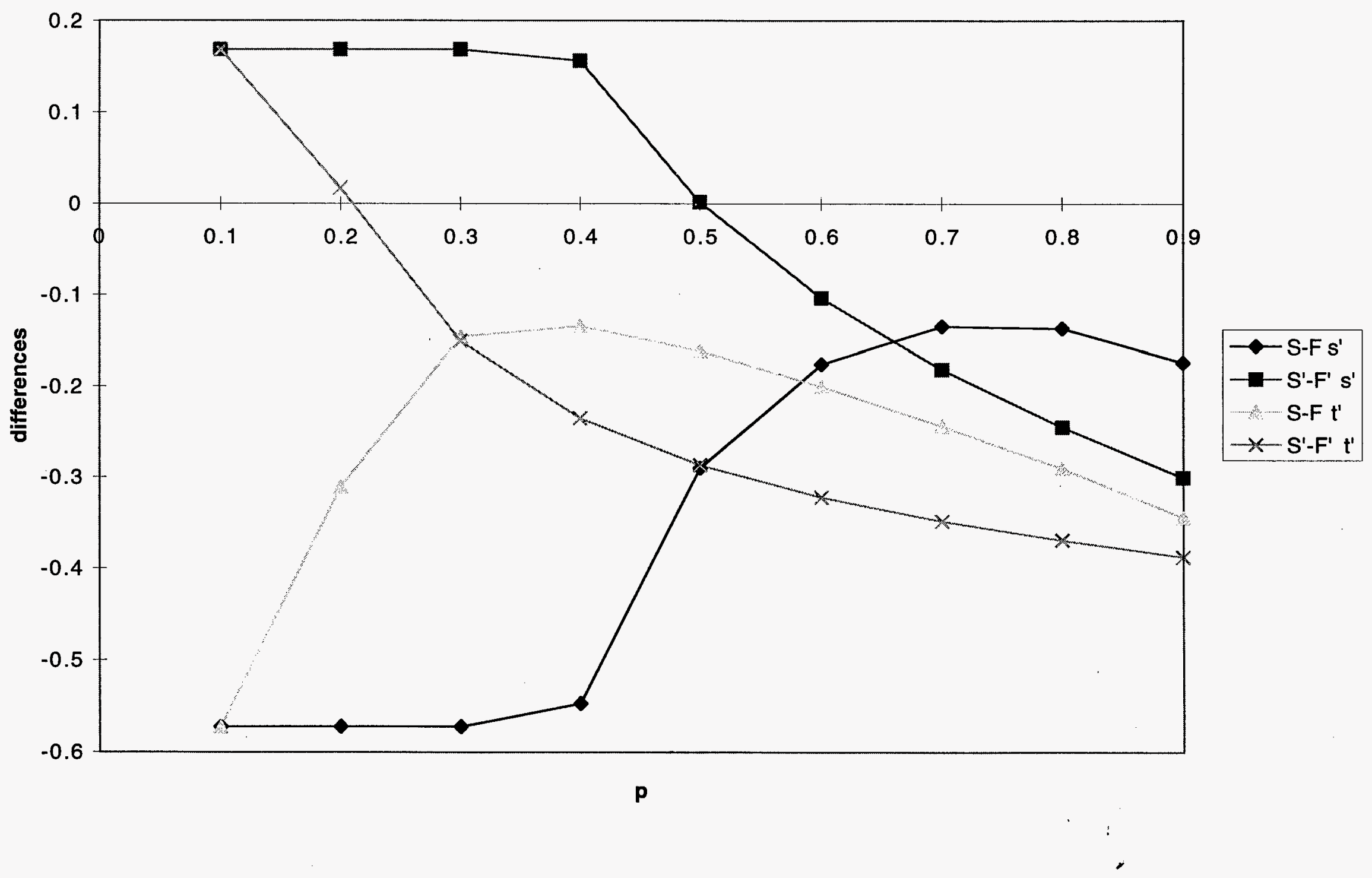


Fig. 5. Singlet stability vs $p$

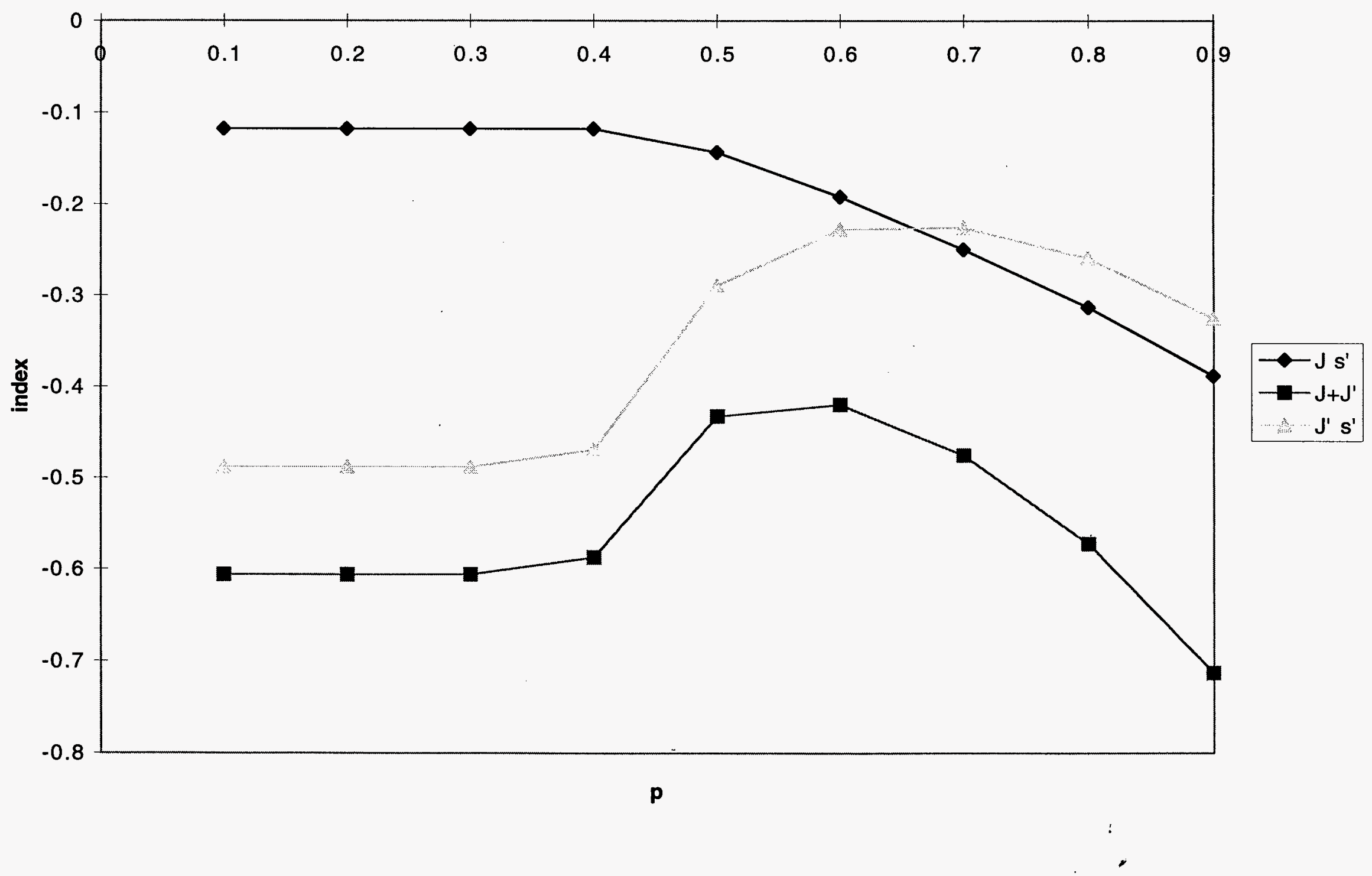

Page 1 


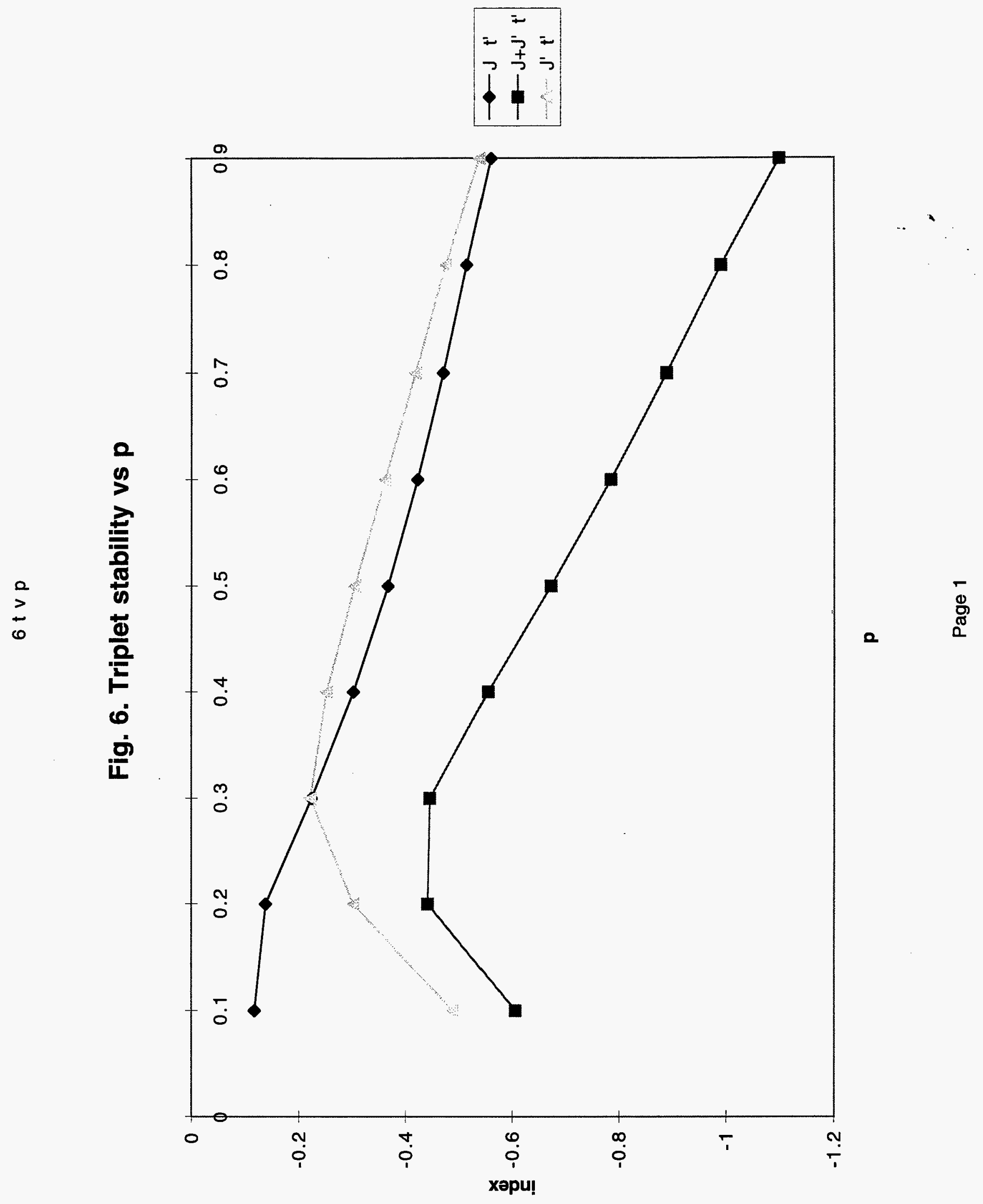




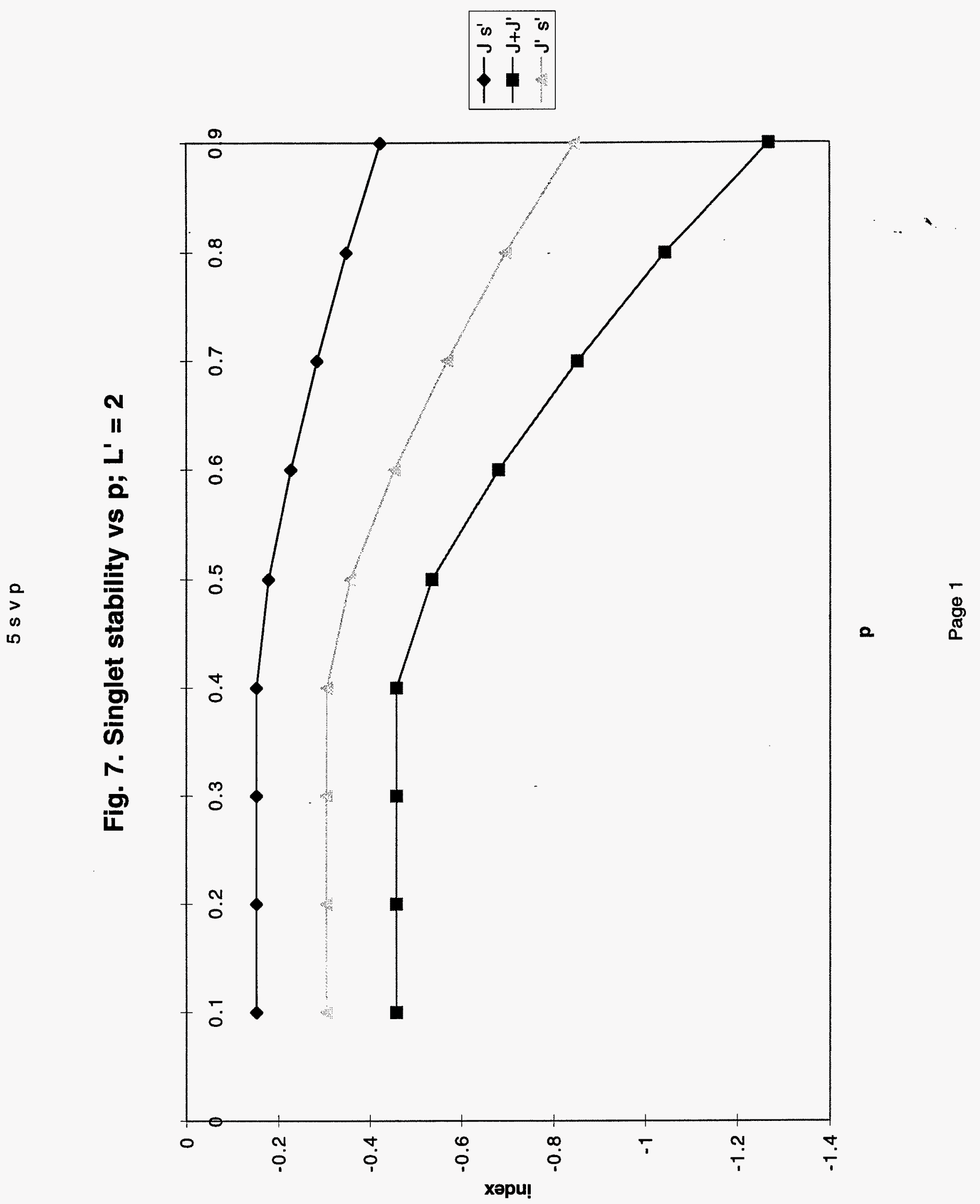




\section{M98004314}

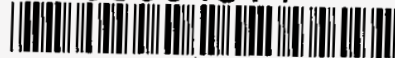

Report Number (14) LA-4R--97-4987

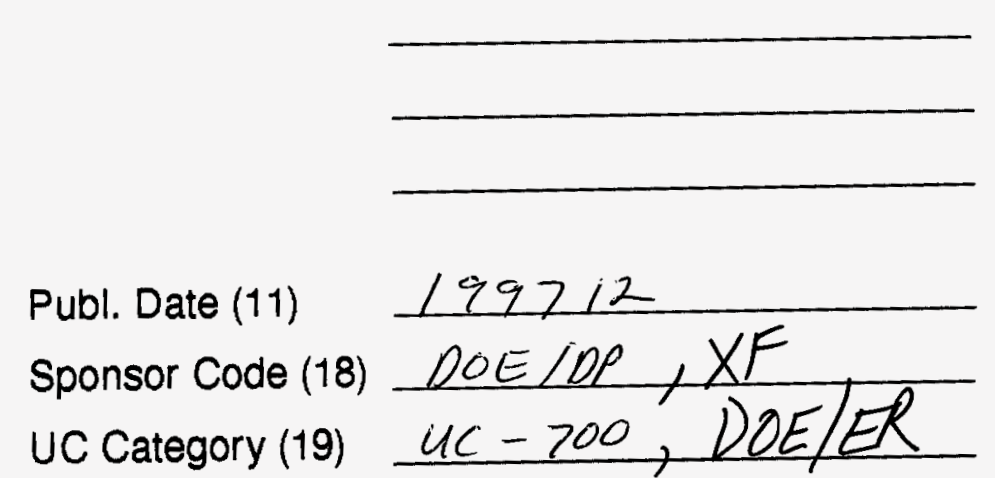

